\title{
Microstuctural Analysis and Optical Properties of Nanocrystalline Cerium Oxides Synthesized by Precipitation Method
}

\author{
Gusliani Eka Putri, Syukri Arief, Novesar Jamarun, Feni Rahayu Gusti, Rahadian Zainul* \\ Syedza Saintika College of Health Sciences, Padang, West Sumatra, Indonesia \\ Department of Chemistry, Andalas University, Padang, West Sumatra, Indonesia \\ Department of Chemistry, FMIPA, Padang State University, Indonesia \\ Email : rahadianzmsiphd@yahoo.com
}

\begin{abstract}
Nanocrystalline cerium oxide is synthesized by precipitation method using a mixture of water solvent and isopropanol with a ratio of 1: 6 at room temperature has been successfully synthesized. Nanocrystalline cerium oxide was characterized by using X-Ray diffraction (XRD), DRS UV-Vis Analytic, scanning electron microscopy (SEM) and transmission electron microscopy (TEM). XRD results showed the peak intensity of Cerium Oxide $(\mathrm{CeO} 2)$ was absorbed at an angle of $2 \Theta$ which is $28.7 \mathrm{o}, 33.2 \mathrm{o}, 47.5 \mathrm{o}, 56.7 \mathrm{o}, 59.2 \mathrm{o}, 69.5 \mathrm{o}, 76.8 \mathrm{o}, 79,1 \mathrm{o}, 88.3$ $\mathrm{o}$, and $95.5 \mathrm{o}$. The size of cerium oxide crystals was calculated using the debye schrerer equation and obtained a crystal size value of $11.04-99.19 \mathrm{~nm}$. Based on the XRD data it can be concluded that the crystal size is included in the nanocrystal category with a size range of 1-100 $\mathrm{nm}$. Microstructure results were analyzed by SEM and TEM showing rounded cerium oxide particles clumping like fine crystals. Optical properties of nanocrystalline cerium oxide were analyzed by DRS UV-Vis Analytic which showed that cerium oxide absorbs UV light at wavelengths of 200,245 and $290 \mathrm{~nm}$ with an energy band gap value of $2.43 \mathrm{eV}$.
\end{abstract}

Keywords: Nanocrystalline, Cerium Oxide, Precipitation

\section{INTRODUCTION}

UV light is in the spectrum range of $200-400 \mathrm{~nm}^{[1]}$. Sunlight radiation is divided into UV-A (320-400nm) and UV-B (270-32 nm) and UV-C (270-290 nm). UV rays from the sun's rays that reach the earth's surface mostly in the form of UV-A and UV-A rays are very dangerous and can cause skin cancer ${ }^{[2]}$. The ability of cerium oxide nanoparticles as a UV light filter material is widely discussed because cerium oxide has better photocatalytic activity than $\mathrm{ZnO}$ and $\mathrm{TiO} 2$. $\mathrm{CeO} 2$ photocatalytic activity is better because $\mathrm{CeO} 2$ has a small refractive index, high absorbance in UV light, high transmittance in visible light and the ability to protect the entire UV spectrum [3].

Oxide nanomaterials have attracted many researchers' attention in recent years because they have good mechanical, electrical, optical and catalyst properties, namely cerium oxide $(\mathrm{CeO} 2)$ commonly known as Ceria. Ceria is one of the interesting oxide nanomaterials in the industrial sector because Ceria has a low refractive index, high oxidation power, $3.2 \mathrm{eV}$ energy band gap, is very sensitive to visible light and has a high absorption of UV radiation ${ }^{[4][5]}$. The ability of cerium oxide to absorb UV light can be increased by reducing crystallite size. Various methods are used to obtain cerium oxide nanoparticles with small crystallite sizes. The process of precipitation in a mixture of aquadest and isopropanol solvents has been carried out to inhibit agglomeration so that small crystallite sizes are obtained ${ }^{[6]}$. In this study synthesis of cerium oxide was carried out using precipitation method by using a mixture of water solvent and isopropanol with a ratio of 1: 6 . Testing of crystallite size and the resulting crystalline absorption peaks were analyzed using XRD. While morphological analysis uses SEM and TEM. Optical properties analysis was carried out with Diffuse Refletance UV-vis .

\section{MATERIALS AND METHODS}

\subsection{Tools and Material}

The equipment used included some glassware, magnetic stirrer, hot plate stirrer, scales, filter paper, aluminum voil, oven, furnace, and buchner funnel. While the instruments used are TEM (Transmission Electron Microscopy), SEM (Scanning Electron Microscopy), XRD (X-Ray Diffraction) and Diffuse Reflectance UV-vis 
(DRS-UV-Vis). $\mathrm{Ce}\left(\mathrm{NO}_{3}\right)_{3} \cdot 6 \mathrm{H}_{2} \mathrm{O}$ (cerium nitrat heksahidrat), isopropanol, amonium hidroksida $\left(\mathrm{NH}_{4} \mathrm{OH}\right)$, all aquadest are pure (pa from Merck).

\subsection{Procedure}

Cerium nitrate hexa hydrate is heated at a temperature of $110^{\circ} \mathrm{C}$ to remove water and then dissolved in a water solvent mixture: isopropanol in a ratio of 1: 6 so that a white mixture is formed. The mixture is white then stirred using a magnetic stirrer for 24 hours. Then the mixture was added to ammonium hydroxide until the $\mathrm{pH}$ was 9 and there was a color change to brownish white. After that, the solution is stirred again using a magnetic stirrer for 3 hours to homogenize the mixture. The solution is left until the precipitate is formed. After the precipitate is formed the precipitate is filtered with a vacuum pump and washed with isopropanol. Then it was dried for 2 hours in an oven at $60^{\circ} \mathrm{C}$. The yellow solids obtained were calcined at $300^{\circ} \mathrm{C}$ for 4 hours using a furnace to form cerium oxide nanocrystalline.

\section{RESULTS AND DISCUSSION}

\subsection{XRD Analysis Results}

The peak intensity of Cerium Oxide (CeO2) was absorbed at a $2 \Theta$ angle of $28.7^{\circ}, 33.2^{\circ}, 47.5^{\circ}, 56.7^{\circ}, 59.2^{\circ}$ ${ }^{\circ}, 69.5^{\circ}, 76.8^{\circ}, 79.1^{\circ}, 88.3^{\circ}$, and $95.5^{\circ}$. Crystal Lattice (110), (200), (220), (311), (222), (400), (331), (420), (422), and (511) based on JCPDS No. 00-043-1002. Very small Kristallities produce very wide diffraction peaks. The width of the diffraction peak produces information on the size of the crystallities. The wider the X-ray diffraction peak, the smaller the size of the crystallites. The diffraction peaks are produced by the constructive interference of light reflected by crystalline planes. The relationship between the size of crystallites with the width of X-ray diffraction peaks can be approximated by the Schrerer equation ${ }^{[6]}$.

$$
\begin{aligned}
& D=\frac{k \lambda}{\beta \operatorname{Cos} \theta} \ldots \ldots \ldots \ldots \ldots \ldots \ldots \\
& \beta=\frac{F W H M \text { Left }\left[{ }^{\circ} 2 T h\right] * \pi}{180} .
\end{aligned}
$$

Based on equations 1 and 2, D is Crystallite site (unit nm), $\boldsymbol{\beta}$ is FWHM (broadening at Half the Maximun Intensity) the value used is the FWHM value after being reduced by the instrumental line broadening (radians), $\Theta$ namely Bragg's Angle, $\lambda$ is X-Ray and k wavelengths are the shape factor constant value (0.8-1). Cerium oxide crystal size $11.04-99.19 \mathrm{~nm}$. Based on research conducted by Goharshadi et al, the radius of Ce3 + crystallite ion is greater than that of $\mathrm{Ce}^{4+}$ ion ${ }^{[7]}$. So it can be indicated that the crystal size of $11.04 \mathrm{~nm}$ is indicated by the form of cerium oxide crystals in the form of $\mathrm{Ce}^{4+}$ while the crystalline size of $99.19 \mathrm{~nm}$ is indicated by the nanocrystalline form of cerium oxide crystals in the form. $\mathrm{Ce}^{3+}$. Based on the results of crystallite size analysis, the size of cerium oxide crystallite has a small size of $100 \mathrm{~nm}$. Based on the results of these calculations shows the success of the synthesis of nanocrystalline cerium oxide because of the size range of nano crystals between 1 $100 \mathrm{~nm}$. 


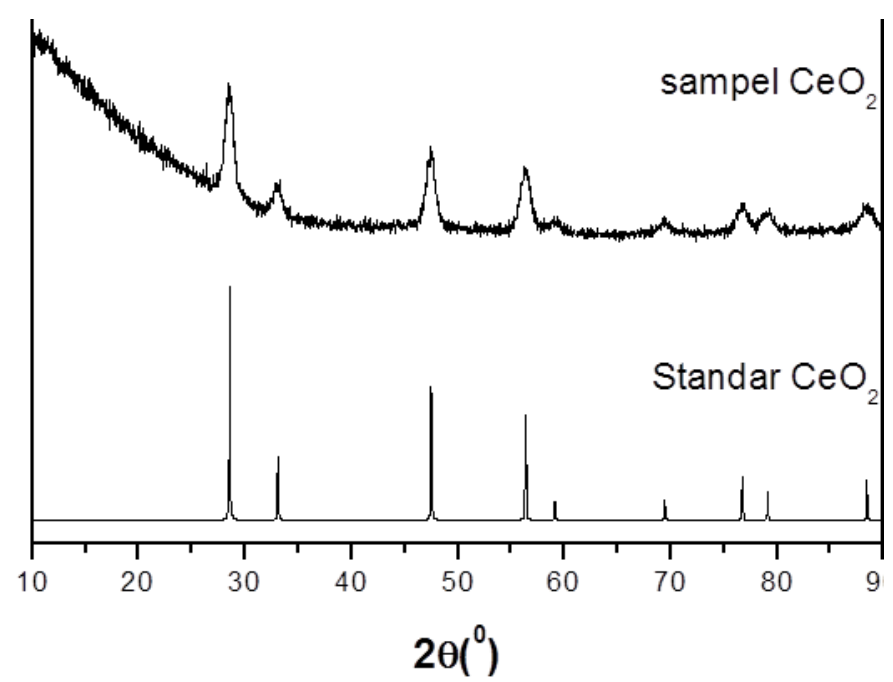

Figure 1. Cerium Oxide XRD Analysis Results

\subsection{Microstuctural Analysis}

\subsubsection{Scanning Electron Microscopy (SEM)}

SEM Cerium Oxide characterization results can be seen from Figure 2 at 500x, 5000x and 10000x magnification. Based on SEM photos in Figure 2, SEM photos of cerium oxide particles showing round shapes scattered throughout the surface of the results of this study are also similar to research conducted by Chinarro et al, $2007^{\text {[4] }}$. SEM image enlargement of $500 \mathrm{x}$ only shows the smooth surface morphology of cerium oxide, the result of $5000 \mathrm{x}$ magnification can be seen that the particle morphology is round but not very clear. While the 10000x magnification is clearly visible in the morphology of round particles with a uniform size.
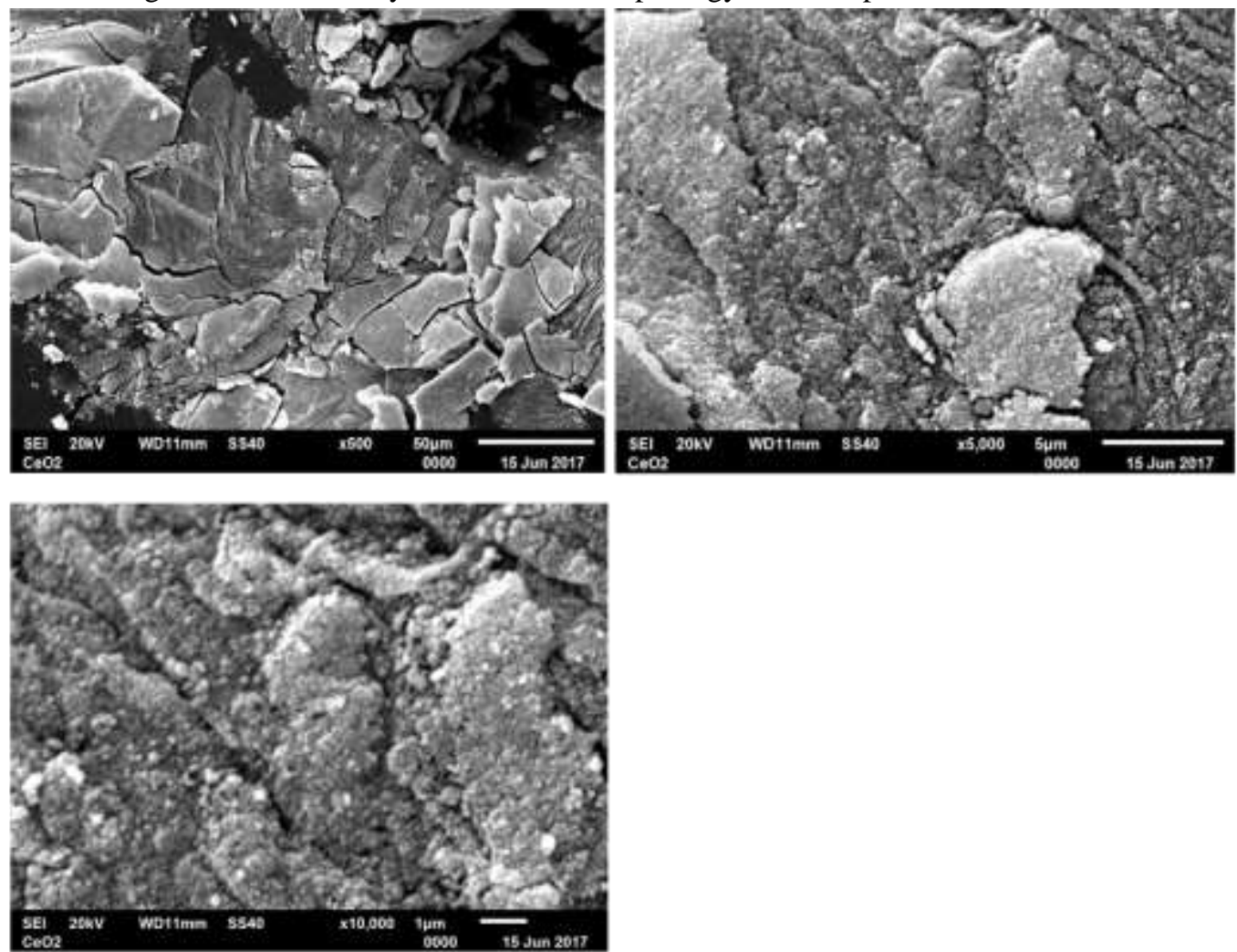

Figure 2. Cerium Oxide SEM Analysis Results with magnification of 500x, 5000x and 1000x 


\subsubsection{Transmission electron microscopy (TEM)}

The results of TEM analysis are used for microstructure analysis, interface analysis, crystal structure and nanometer scale elemental analysis. Pore size determination can be done by measuring the TEM image from the vertical direction (face appearance) and horizontal direction (side view). The results of the TEM analysis in Figure 3 show that (spherica)l particles clump like fine crystals, this results in line with the study of Chinarro et al, 2007 which explains that the cerium oxide obtained is also spherical ${ }^{[4]}$.
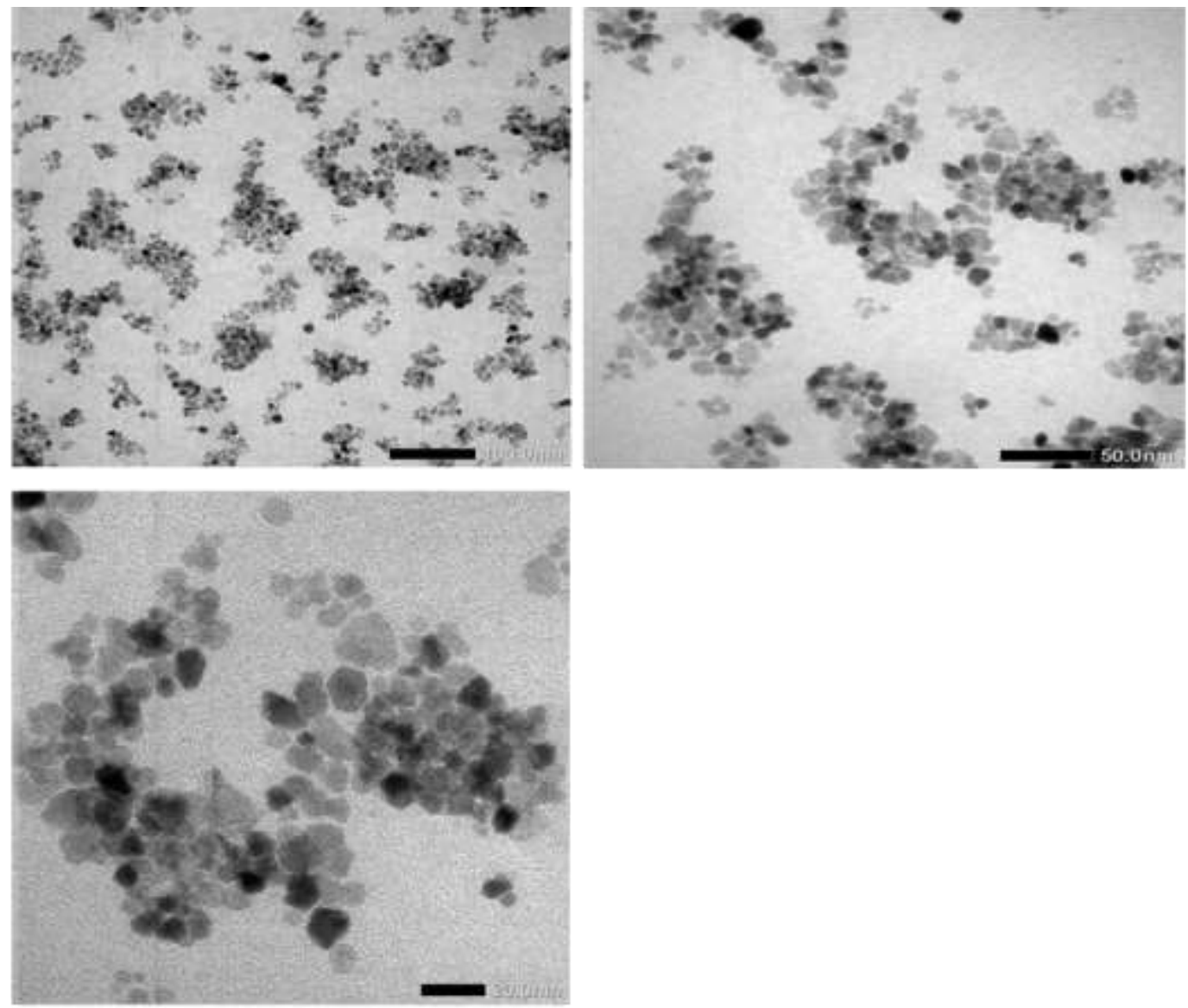

Figure 3. The results of the Cerium Oxide TEM analysis

Particle size distribution is calculated using the application image J. Data obtained from the $\mathbf{J}$ image is processed using microsoft excel so that the program curve is obtained. Based on Figure 4 it can be concluded that the particle size of Ceria is 7-10 nm. This result is in line with the research of Gohasardi et al which produced cerium oxide nanomaterials with a particle size of $7 \mathrm{~nm}^{[7]}$. 


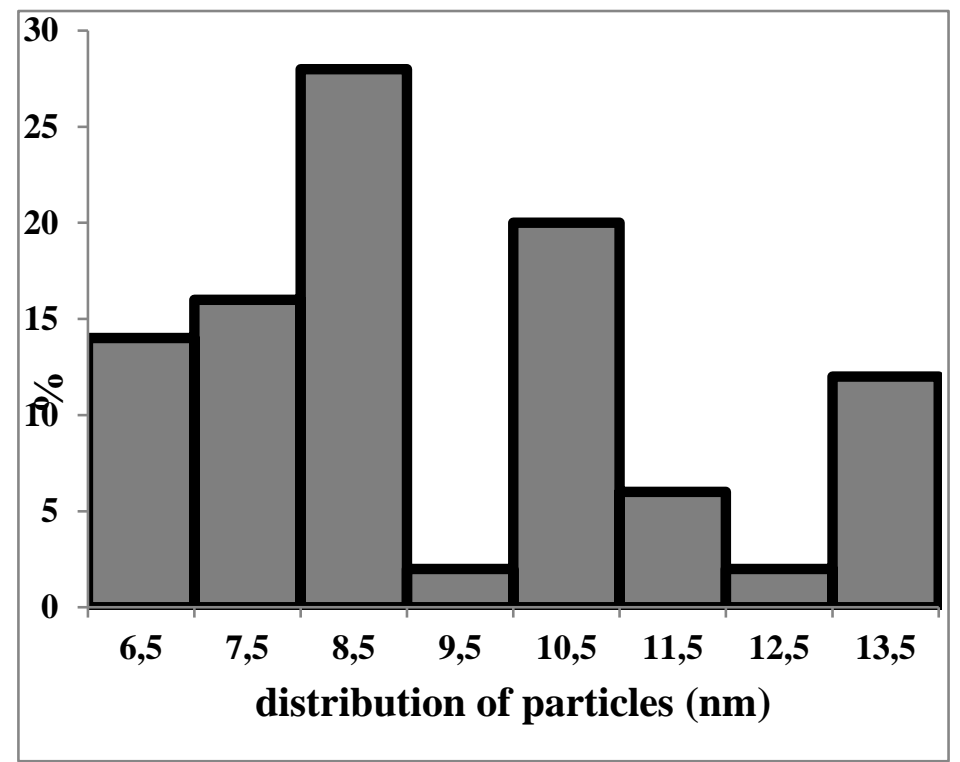

Figure 4. distribution of Cerium Oxide particles

\subsubsection{Analysis of Optical Properties with DRS UV-Vis Analytic}

UV light has a wavelength of 200-400 $\mathrm{nm}$. The results of DRS UV-Vis analysis for absorbance showed that Nanocrystalline Cerium Oxide samples were absorbed at $200 \mathrm{~nm}, 245 \mathrm{~nm}$ and $290 \mathrm{~nm}$. Absorption absorbance ends at a wavelength of $500 \mathrm{~nm}$. These results indicate that nanocrystalline cerium silica oxide absorbs in the UV light region until the visible light region.

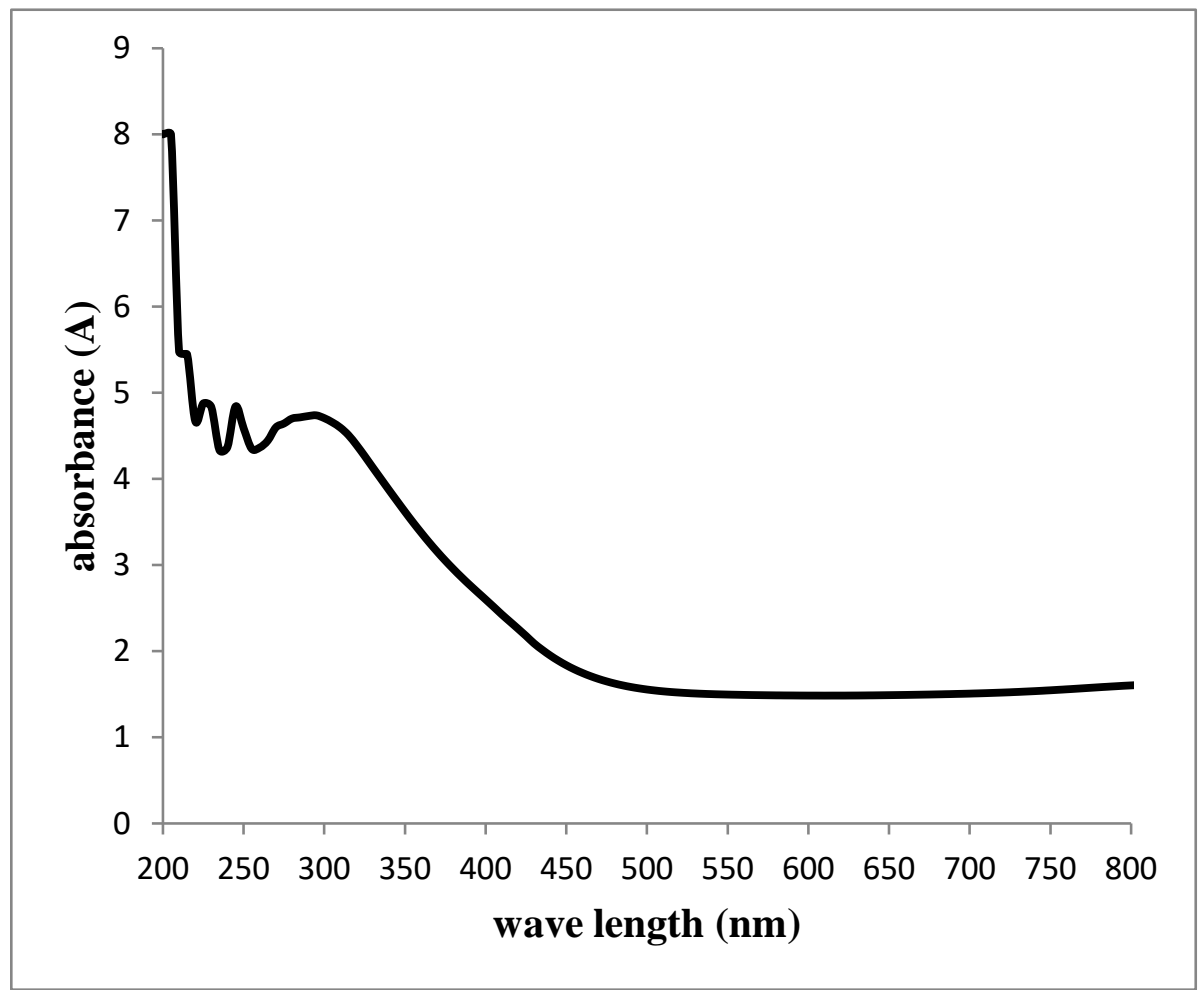

Figure 5. Results of DRS-UV Vis Absorptions of Cerium Oxide 
Determination of optical band gap energy is done by using the reflactant value from the DRS-UV Vis analysis. The \% refractant value (\% R) is made into the $\mathrm{y}$ axis by changing it to $\mathrm{R}$. The value of the wavelength $(\lambda)$ from the results of the reflactant analysis with the DRS-UV Vis tool is included in the Kubelka Munk equation, equation 3 , after which the value of hv is sought by the equation 4 where $\mathrm{h}$ is the plank constant $=6.626 \mathrm{x} 10-34$ Js and C is the speed of light with a value of $3 \times 108 \mathrm{~m} / \mathrm{s}$. The value of alpha square ((1-R) $2 / 2 \mathrm{R} \times \mathrm{hf}) 2$ for each wavelength $(\lambda)$ is made into the $y$ axis and then plotted into the graph with the $\mathrm{x}$-axis Energy value in units of $\mathrm{eV}$ ${ }^{[8.9 .10]}$. After making a graph the relationship between alpha square ((1-R) $\left.2 / 2 \mathrm{R} x \mathrm{hf}\right) 2$ with the hv value drawn by a line that intersects with the turning point on the curve as shown in Figure 6.

$$
\begin{array}{r}
F(R)=\frac{(1-R)^{2}}{2 R} \ldots \\
E=\frac{h \cdot C}{\lambda}
\end{array}
$$

In nanomaterials the size of the material is very small so that the surface area becomes large. Energy band gap width is inversely proportional to particle size. The smaller the particle size, the greater the value of the energy band gap. The greater the value of the energy band gap, the slower the recombination process will occur, so that the excitation process lasts longer than the recombination process, so that more organic compounds can be degraded. The smaller the particle size, the more reactivity will increase because the smaller the particle size, the greater the surface area will cause the atomic fraction will be more on the surface while a material reacts with other materials on the surface ${ }^{[10,11]}$, so that the more atomic fractions on the surface the material reactivity will increase. The bulk band gap value of cerium oxide is ranging from 2.8 to $3.2 \mathrm{eV}$. Based on the results of the calculation of the energy band gap value in accordance with Figure 6, the value of the energy band gap decreased to $2.43 \mathrm{eV}$.

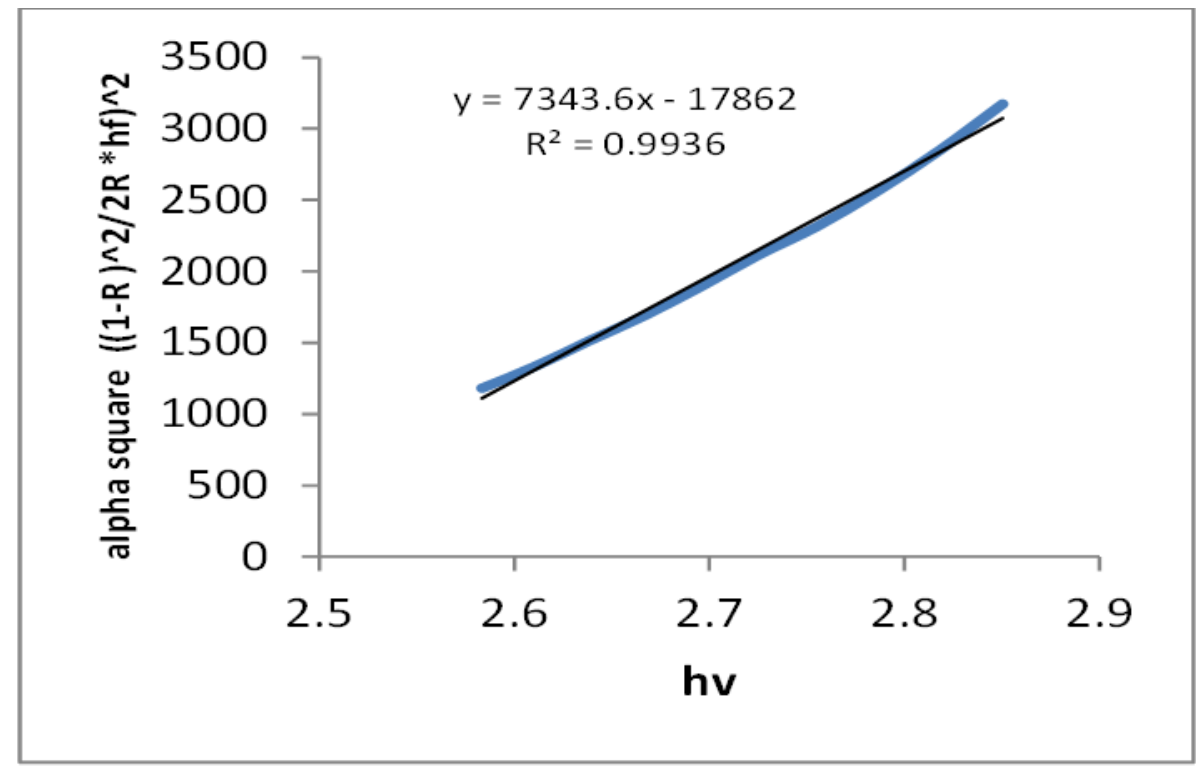

Figure 6. Curve Determining the Energy Value of the Optical Band Gap using the Kubelka-Munk Theory of Optical Cerium Oxide

\section{CONCLUSION}

Synthesis of cerium oxide with precipitation method using a mixture of aquadest and isopropanol solvents with a ratio of 1: 6 has been successfully synthesized. The size of crystallite from XRD analysis ranged between $11.04-99.19 \mathrm{~nm}$. based on the XRD data it can be concluded that the crystal size is included in the nanocrystal category with a size range of $1-100 \mathrm{~nm}$. The size of the crystal is inversely proportional to the value of the energy band gap so that when the size of cerium oxide is smaller (nano), the value of the band gap is increased to 2.43 
$\mathrm{eV}$. The results of SEM and TEM analysis showed that the morphological form of cerium oxide was (spherica)l with a size of 7-10 $\mathrm{nm}$.

\section{ACKNOWLEDGMENTS}

Acknowledgments the authors say to the Directorate of Research and Community Service (DRPM) DIKTI who have funded this research through research grants for collaboration between universities (PEKERTI). Thank you to Kopertis Wilayah X and Stikes Syedza Saintika for supporting this research. 


\section{BIBLIOGRAPHY}

[1] El-Toni, A.M,Yin, Shu and Sato Tsugio, UV Shelding performance Enhancement of Cao Doped Ceria by Coupling with Plate-Like K0.8Li0.27Ti1.7304, Journal Mater Science. 43: 2411-2417, (2008).

[2] Minamidate, Y, Yin S, and Sato T, Synthesis and Characterization Of Plate-Like Ceria particles for Cosmetic Application. Materials Chemistry and Physics Scince Direct, 516-520(2010).

[3] V. Mirkhani, S. Tangestaninejad, M. Moghadam, M. H. Habibi, andA. Rostami-Vartooni. , Photocatalytic degradation of azo dyescatalyzed by Ag doped $\mathrm{TiO} 2$ photocatalyst, Journal of the Iranian Chemical Society, 6: 578-587. (2009).

[4] Chinaro, E.C, Jurado, J.R., Colomer, M.T. Syntesis Of Ceria Based Electrolyte Nanometric Powders By Urea-Combustion Technique. Journal Of The European Society, 6842, 5, (2007).

[5] Sen, Ranjan, Das, Sidartha and Das, Karabi, nb Microstuctural Characterization of Nanosized Ceria Powder by X-Ray diffraction Analysis, Departemen of Metallurgical and Materials Engineering, Indian Institite Of Technology, Kharagpur, India.

[7] Goharshadi, Elaheh, k, Samiee, Sara and Nancraw, Paul. Fabrication of Cerium Oxide, Fabrication of Cerium Oxide Nanoparticles : Characterization and Optical properties. Journal of Colloid and Interface Science Direct. 356 : 473-480, (2011)

[8]Bing, J.,Li, L.,Lan B., Liao, G.,Zeng, J., Zhang, Q., \& Li, X. 2012 .Synthesis of Cerium-doped MCM-41 for ozonations of p-chlorobenzoic Acid in Aqueus Solution, Applied Catalysis B : Enviromental 115-112.16-24.

[9] Chen, H.I, Chang, H.Y,Syntesis of nanocrystalline crium oxide Particles by The Precipitation Method. Science Direct Ceramic Internasional, 31: 795-802, (2005)

[10] Yang H, Huang, C, tang, A,Zhang,X, Yang, W, Microwave -Asiited Synthesis Of Ceria nanoparticles. Science Direct Material research Bulletin, 40; 1690-1695. (2005).

[11] Wu, G. and Zaefferer, S, Advances in TEM orientation microscopy by combination of darkfield conical scanning and improved image matching. Ultramicroscopy, 109, 1317-1325, (2009).

[12] Bharali, P.B.,Saikia, P.S., Reddy, B.M.R. 2012. Large Scale Synthesis Of Ceria-Based Nano-Oxides with Hight CO oxidations Activity. Journal of cataliyst Science And Technology. 2.931-933 